\title{
Pyrazole Derivatives Induce Apoptosis via ROS Generation in the Triple Negative Breast Cancer Cells, MDA-MB-468
}

\author{
Maryam Ashourpour ${ }^{1}$, Fatemeh Mostafavi-Hosseini ${ }^{1}$, Mohsen Amini ${ }^{2}$, Ebrahim \\ Saeedian Moghadam², Faranak Kazerouni ${ }^{1 *}$, Seyed Yousef Arman ${ }^{3}$, Zahra \\ Shahsavari ${ }^{4 *}$
}

\begin{abstract}
Background: Triple-negative breast cancer accounts for approximately $15-20 \%$ of all breast carcinomas and is associated with earlier age of onset, aggressive clinical course, and dismal prognosis. A series of 1,3-diaryl-5-(3,4,5trimethoxyphenyl)-4,5-dihydro-1 H-Pyrazole and 1,3-diaryl-5- (3,4,5-trimethoxyphenyl)- 1 H-Pyrazole were evaluated for their anticancer activity against MDA-MB-468, human triple negative breast cancer cell line. Methods: The cytotoxic effects of Pyrazole derivatives on the growth of MDA-MB-468 and AGO1522 were determined using MTT assay. Annexin-V-FITC and PI staining were performed to detect apoptosis and cell cycle distribution using Flow cytometry. The level of Reactive oxygen species (ROS) formation and caspase 3 activity were determined accordingly. Results: Pyrazole derivatives induced a dose and time-dependent cell toxicity in MDA-MB-468 compared with untreated cells. The results showed that 3-(4-methoxyphenyl)-1-(p-tolyl)-5-(3,4,5-trimethoxyphenyl)-4,5-dihydro-1H-Pyrazole (3f) was the most active compound with $\mathrm{IC}_{50}$ values $14.97 \mu \mathrm{M}$ and $6.45 \mu \mathrm{M}$ compared with Paclitaxel with $\mathrm{IC}_{50}$ values 49.90 $\mu \mathrm{M}$ and $25.19 \mu \mathrm{M}$, after 24 and 48 hours, respectively. Upon treatment with $14.97 \mu \mathrm{M}$ of $3 \mathrm{f}$ after $24 \mathrm{~h}$, the compound induced cell cycle arrest in $\mathrm{S}$ phase. $3 \mathrm{f}$ provoked apoptosis was accompanied by the elevated level of ROS and increased caspase 3 activity in MDA-MB-468 cells compared with untreated cells. Conclusion: The overall results of the present study provided evidence for the cytotoxicity of compound $3 \mathrm{f}$ against MDA-MB-468 cells in comparison to reference standard, Paclitaxel. It proves that compound $3 \mathrm{f}$ can trigger apoptosis through ROS production and caspase 3 activation. These bring supportive data for future investigations that will lead to their use in cancer therapy.
\end{abstract}

Keywords: Pyrazole derivatives- TNBC- Apoptosis- ROS

Asian Pac J Cancer Prev, 22 (7), 2079-2087

\section{Introduction}

Breast cancer is one of the most common cancers among women and is a major reason for cancer death worldwide (Rakha et al., 2010). According to the literature, the incidence of female breast cancer in various countries was accounted for up to 3.2 million new cases per year by 2050 (Tao et al., 2015). Basically, breast cancer is a heterogeneous complex of diseases which involve a broad spectrum of subtypes (Yersal and Barutca, 2014). By the way illustration, luminal A (ER+and/or PR+, HER-2- ), luminal B (ER+and/or PR+, HER-2+), HER2-enriched (ER-, PR-, HER-2+), basal-like (ER-, PR-, HER-2- ) and normal-like are five biologically distinct intrinsic subtypes based on gene expression profiling classification (Liu et al., 2014; Jiang et al., 2019). The complex nature of breast cancer corresponds to distinct biological features results in various responses to different treatments. Since most basal-like tumors lack expression of hormone receptors (HR) and overexpression and/or amplification of HER2, triple-negative breast cancer (TNBC) refers to basal-like classification (Prat et al., 2013). Therefore, the design, development, and implementation of potential therapeutic molecules along with unveiling the myriad of questions arising from the interaction of TNBC biological cells/drugs has been an area of intensive research in cancer drug discovery (Sebastian et al., 2016). Among organic compounds, Pyrazoles have gained attention as

\footnotetext{
${ }^{1}$ Department of Laboratory Medicine, Faculty of Paramedical Sciences, Shahid Beheshti University of Medical Sciences, Tehran, Iran. ${ }^{2}$ Department of Medicinal Chemistry, Faculty of Pharmacy and Drug Design \& Development Research Center, The Institute of Pharmaceutical Sciences, Tehran University of Medical Sciences, Tehran, Iran. ${ }^{3}$ School of Chemistry, Australian Centre for Nano Medicine and the ARC Centre of Excellence in Convergent Bio-Nano Science and Technology, The University of New South Wales, Kensington, New South Wales, Australia. ${ }^{4}$ Department of Clinical Biochemistry, Faculty of Medicine, Shahid Beheshti University of Medical Sciences, Tehran,Iran.*For Correspondence: z.shahsavari@sbmu.ac.ir;f_kazerouni@sbmu.ac.ir.Maryam Ashourpour and Fatemeh Mostafavi-Hosseini have equal contribution in this study.
} 
promising scaffolds in the field of medicinal chemistry (Saueressig et al., 2018). Possessing unique properties like anticancer, antiangiogenic, and anti- metastatic action, Pyrazole derivatives deserve credit for their varied biological activities (Lehmann et al., 2017). Different Pyrazole derivatives including phenazone, metamizole, aminopyrine, phenylbutazone, sulfinpyrazone and oxyphenbutazone are readily available anti-inflammatory drugs (Prabhu et al., 2018). In this regard, Viagra , Celecoxib and Fipronil containing highly substituted Pyrazole ring have been commercialized as an effective ligand for estrogen receptors (Ananda et al., 2018). Sun et al., (2018) have reported the strong anti-tumor activity of these compounds for human lung cancer cell lines, A549. The anticancer efficiency of Pyrazole derivatives is reportedly connected to inhibition of several targets in cancer cells through interaction with topoisomerase II, EGFR, VEGF, HDAC, IGF-1R, Aurora-A kinase, cMet, Tubulin, mTOR, B-raf, CDKs, PI3K, JAK2, ALK, among others (Alam et al., 2016). Despite the fact that investigation pertinent to the antitumor activity of Pyrazole derivatives does not exceed two decades, the effectiveness of these compounds in the treatment of various cancers has been reported by many researchers. For instance, ruxolitinib (a selective inhibitor of JAK1 and JAK2), crizotinib (a c-Met and ALK inhibitor) and AT7519 (an inhibitor of cyclin-dependent kinases) have been reported for treatment of myelofibrosis, nonsmall cell lung carcinoma and refractory solid tumors respectively (Nitulescu et al., 2015). Based on published data, Pyrazoles induce cytotoxicity to human cancer cells through apoptosis pathway. The present work aims to evaluate the anticancer properties of Pyrazole derivatives against MDA-MB-468 triple negative breast cancer cell line.

\section{Materials and Methods}

\section{Materials}

We used all chemicals as analytical grades without any further purification. Dulbecco's modified Eagle's medium/nutrient F-12 Ham (DMEM/Ham's F12), Dulbecco's Modified Eagle's Medium-low glucose (DMEM/Low Glucose), Fetal bovine serum (FBS), Penicillin-streptomycin (P/S), phosphate-buffered saline (PBS) and $0.25 \%$ trypsin-Ethylenediaminetetraacetic acid (EDTA), Dimethyl sulfoxide (DMSO) were obtained from Gibco (Grand Island ,NY,USA); 3-(4,5-dimethylthiazol-2yl)-2,5-diphenyltetrazolium bromide (MTT), Fluorescent probe 2',7'dichlorofluorescin diacetate (DCFH-DA) and Propidium iodide (PI) were obtained from Sigma-Aldrich (Munich, Germany). Annexin V-FITC apoptosis detection kit and Caspase-3/CPP32 Fluorometric Assay Kit were obtained from BioVision Research Products (Mountain View, CA, USA). The human breast cancer cell line, MDA-MB-468 and the normal human fibroblast cell line, AGO1522 were obtained from the Iranian Biological Resource Center (IBRC, Tehran, Iran).

\section{Cell culture}

The MDA-MB-468 cells were maintained in
DMEM/Ham's F12 supplemented with L-glutamine, with $10 \%$ fetal bovine serum and $1 \%$ penicillin/streptomycin. The AGO1522 cell line was cultured in DMEM/Low Glucose, with $10 \%$ fetal bovine serum and $1 \%$ penicillin/ streptomycin. Cells were incubated at $37^{\circ} \mathrm{C}, 5 \% \mathrm{CO} 2$ and every 2-3 days at the confluency of $80 \%$, the cells were harvested from the culture flask by Trypsin-EDTA.

\section{Cell viability assay}

Cell viability was measured with the MTT assay. The reduction of the tetrazolium salt, to a blue formazan crystal is facilitated by mitochondrial dehydrogenase and NADPH-dependent cellular oxidoreductase enzymes (Abel and Baird, 2018). In the assay, an aliquot of $7.5 \times 10^{3}$ cells was seeded on the 96 -well plates and allowed to attach overnight. Then, 11 Pyrazole derivatives (as shown in Table 1 and Figure S1) were added to the desired well with the final concentration of $3,6.25,12.5$, $25,50,100 \mu \mathrm{M}$. After pre-treating cells for 24 and $48 \mathrm{~h}$, MTT ( $5 \mathrm{mg} / \mathrm{ml}$ in PBS) was added to each well and the cells were incubated for another $4 \mathrm{~h}$ at $37^{\circ} \mathrm{C}$. In order to dissolve blue-colored formazan crystals, the entire medium was aspirated after the incubation period, and DMSO was added to the wells. An ELISA plate reader (BioTek Instruments, Inc., USA) was used to quantify the formazan concentration (with the wavelengths of $570 \mathrm{~nm}$ ). All of the experiments were carried out on three replicates to ensure the measurement repeatability and the $\mathrm{IC}_{50}$ values were also calculated using GraphPad Prism software.

\section{Detection of apoptosis using annexin V/PI staining}

Annexin V-FITC/PI Apoptosis Detection Kit was employed to detect apoptosis. To assess the number of apoptotic cells, an aliquot of MDA-MB-468 cells was adjusted to obtain $2 \times 10^{5}$ cells per well in six-well plates followed by incubation for an overnight. After incubation cells on the surface for an appropriate time, compound $3 \mathrm{f}$ was added to the wells to obtain the final concentration of $14.7 \mu \mathrm{M}$ in wells for $24 \mathrm{~h}$. Cells were then harvested from the culture wells by aspirating media and washing with ice-cold PBS. Once the cells have detached, resuspended cells were pipetted up and down thoroughly followed by transferring to a sterilized $5 \mathrm{ml}$ centrifuge tube. After $15 \mathrm{~min}, 400 \mu \mathrm{l}$ of the binding buffer was added to the cell suspension. Then annexin V-FITC and PI staining solution were added to the tubes. The cell suspension was then placed in a dark place (10 min at room temperature). A flow cytometer (BD Biosciences, San Jose, CA) was used to analyze the cells. The analysis of data was made using FlowJo software.

\section{Cell cycle analysis}

Cell cycle analysis was conducted through taking advantage of PI staining and flow cytometry analysis. To evaluate cellular DNA levels, the cells stained with PI were subjected to flow cytometric analyses. In this assay, six-well plates were loaded with $2 \times 10^{5}$ MDA-MB-468 cells / well. After incubation of the samples at $37^{\circ} \mathrm{C}$ for $24 \mathrm{~h}$, cells were treated with $3 \mathrm{f}$ at concentrations of 14.7 $\mu \mathrm{M}$ followed $24 \mathrm{~h}$ incubation. Then, the effect of the drug became evident and cells collected by rinsing with PBS 
(two times), immobilizing with $70 \%$ ice-cold ethanol (for $3 \mathrm{~h}$ ), and washing with PBS (two times). To resuspend the cells a mixture of $0.25 \mathrm{ml}$ PBS containing $5 \mu \mathrm{lof} 10 \mathrm{mg} /$ $\mathrm{ml}$ RNase A and Triton X-100 (0.1\%) including $10 \mu \mathrm{l}$ of PI $(50 \mu \mathrm{g} / \mathrm{ml})$ was used and incubation was performed at $37^{\circ} \mathrm{C}$ for $30 \mathrm{~min}$ in a dark place. The assessment of stain cells was carried out employing a FACS Calibur flow cytometer (BD Biosciences, San Jose, CA). The apoptotic rate of the cell population was measured by calculating the percentage of cells with sub-G1 DNA content.

Detection of intracellular reactive oxygen species (ROS)

The level of intracellular ROS corresponded to the MDA-MB-468 cells in response to the $3 f$ compound was monitored by using DCFH-DA. Briefly, $7.5 \times 10^{3}$ MDA-MB-468 cells were seeded per well of 96-wells plate and allowed to attach to the bottom of the wells for an overnight followed by treatment with $3 \mathrm{f}$ compound at a concentration of $14.7 \mu \mathrm{M}$. After incubation of cells for $24 \mathrm{~h}$, PBS was used for rinsing and then cells incubated in the presence of DCFH-DA for $30 \mathrm{~min}$ at $37^{\circ} \mathrm{C}$. Next, to remove the extracellular DCFH-DA, cells were washed three times with prechilled PBS. Finally, the fluorescent of collected cells was analyzed by using a fluorescent microplate reader (BioTek Synergy HT, Winooski, VT, USA).

\section{Determination of caspase-3 activity}

From a mechanistic point of view, caspase 3 as a member of the cysteine-aspartic protease family is essential for a variety of biological activities, including apoptosis in mammalian cells (Skiba et al., 2019). To confirm the drug triggers apoptosis, the level of 7-amino4-trifluoromethyl-coumarin (AFC) from DEVD-AFC, a marker of caspase 3 activation, was measured using Caspase-3/CPP32 Fluorometric Assay Kit (BioVision Research Products, Mountain View, CA, USA). Briefly, MDA-MB-468 cells (a density of $7.5 \times 10^{3}$ per well in 96-wells plate) were treated with $14.97 \mu \mathrm{M} 3 \mathrm{f}$ for $24 \mathrm{~h}$. The following day, cells were collected, washed two times in PBS and lysed in lysis buffer (for 10 min on ice). The concentration of protein was assessed and $50 \mu \mathrm{L}$ of supernatant containing 50-200 $\mu \mathrm{g}$ protein was added to the $50 \mu \mathrm{L}$ of $2 \mathrm{x}$ reaction buffer and $5 \mu \mathrm{l}$ of DEVD-AFC substrate $(1 \mathrm{mM})$, in a 96 -wells plate. The mixture was then left at $37^{\circ} \mathrm{C}$ for 2 hours followed by monitoring the fluorescence intensity using a fluorescent microplate reader (BioTek Synergy HT, Winooski, VT, USA).

\section{Statistical analysis}

All experiments were carried out on three replicates and the data including uncertainties were presented as Mean \pm SD. All data analysis was performed using GraphPad Prism software 6 (CA, USA). A one-way analysis of variance followed by Dunnett's test was used to compare the data between the groups. A value of $p<0.05$ was considered significant.

\section{Results}

3 inhibits $M D A-M B-468$ cells proliferation in a dose- and time-dependent manner

The cytotoxic effect of compounds on MDA-MB-468 and AGO1522 were studied by in vitro MTT assay with Paclitaxel as the standard. Regardless of concentration, a drop in cell viability occurred in a time-dependent manner for all compounds indicating the effectiveness of drugs compared with the untreated control sample (Table 2). The observation would suggest the superior activity offered by $3 \mathrm{f}$ compound among the other synthesized compounds on the MDA-MB-468 breast cancer cell line. The $\mathrm{IC}_{50}$ value of MDA-MB-468 correspond to the $3 \mathrm{f}$ compound after 24 , and $48 \mathrm{~h}$ treatment were recorded $14.97 \mu \mathrm{M}$ and $6.4 \mu \mathrm{M}$ while with those of control drug Paclitaxel were $49.9 \mu$ and $25.19 \mu \mathrm{M}$, respectively. Further inspection of the results revealed $3 \mathrm{f}$ compound not only induces the maximum inhibitory growth on breast cancer cells (MDA-MB-468) but also the minimum toxicity on normal fibroblast cell line (AGO1522) indicating the effectiveness of this compound on inhibiting human triple negative breast cancer cells.

\section{Compound 3 induces apoptosis in MDA-MB-468 breast cancer cells \\ To provide a better understanding of the cytotoxicity mechanism behind the $3 \mathrm{f}$ compound, we used flow cytometry following annexin V-FITC/PI double staining. From the data presented in Figure 1a, the apoptosis value corresponds to MDA-MB-468 cells in the presence of compound $3 \mathrm{f}(14.97 \mu \mathrm{M})$ after $24 \mathrm{~h}$ compared with the}

Table 1. Pyrazole Derivatives Characteristics

\begin{tabular}{|c|c|c|c|c|}
\hline & & Molecular weight (g/mol) & $\mathrm{R} 1$ & $\mathrm{R} 2$ \\
\hline $3 a$ & 1,3-diphenyl-5-(3,4,5-trimethoxyphenyl)-4,5-dihydro-1H-Pyrazole & 388.46 & $\mathrm{H}$ & $\mathrm{H}$ \\
\hline $3 b$ & 3-phenyl-1-(p-tolyl)-5-(3,4,5-trimethoxyphenyl)-4,5-dihydro-1H-Pyrazole & 402.49 & $\mathrm{H}$ & $\mathrm{Me}$ \\
\hline $3 \mathrm{c}$ & 1-(4-chlorophenyl)-3-phenyl-5-(3,4,5-trimethoxyphenyl)-4,5-dihydro-1H-Pyrazole & 422.9 & $\mathrm{H}$ & $\mathrm{Cl}$ \\
\hline $3 \mathrm{~d}$ & 1-(4-fluorophenyl)-3-phenyl-5-(3,4,5-trimethoxyphenyl)-4,5-dihydro-1H-Pyrazole & 406.45 & $\mathrm{H}$ & $\mathrm{F}$ \\
\hline $3 e$ & 3-(4-methoxyphenyl)-1-phenyl-5-(3,4,5-trimethoxyphenyl)-4,5-dihydro-1H-Pyrazole & 418.49 & $\mathrm{OMe}$ & $\mathrm{H}$ \\
\hline $3 f$ & 3-(4-methoxyphenyl)-1-(p-tolyl)-5-(3,4,5-trimethoxyphenyl)-4,5-dihydro-1H-Pyrazole & 432.52 & $\mathrm{OMe}$ & $\mathrm{Me}$ \\
\hline $3 g$ & 1-(4-chlorophenyl)-3-(4-methoxyphenyl)-5-(3,4,5-trimethoxyphenyl)-4,5-dihydro-1HPyrazole & 452.93 & $\mathrm{OMe}$ & $\mathrm{Cl}$ \\
\hline $4 \mathrm{a}$ & 1,3-diphenyl-5-(3,4,5-trimethoxyphenyl)-1H-Pyrazole & 386.45 & $\mathrm{H}$ & $\mathrm{H}$ \\
\hline $4 \mathrm{~b}$ & 3-(4-methoxyphenyl)-1-(p-tolyl)-5-(3,4,5-trimethoxyphenyl)-1H-Pyrazole & 416.47 & $\mathrm{OMe}$ & $\mathrm{Me}$ \\
\hline $4 \mathrm{c}$ & 1-(4-chlorophenyl)-3-(4-methoxyphenyl)-5-(3,4,5-trimethoxyphenyl)-1H-Pyrazole & 450.91 & $\mathrm{OMe}$ & $\mathrm{Cl}$ \\
\hline $4 \mathrm{~d}$ & 1-(4-fluorophenyl)-3-(4-methoxyphenyl)-5-(3,4,5-trimethoxyphenyl)-1H-Pyrazole & 434.46 & $\mathrm{OMe}$ & $\mathrm{F}$ \\
\hline
\end{tabular}




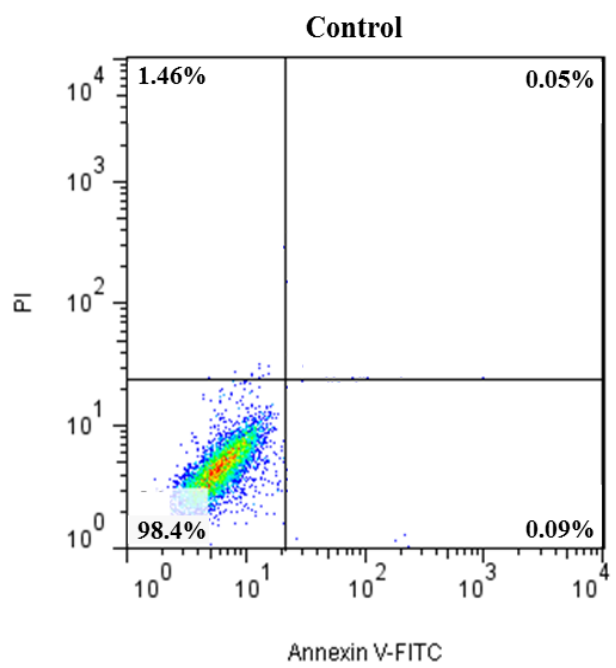

b

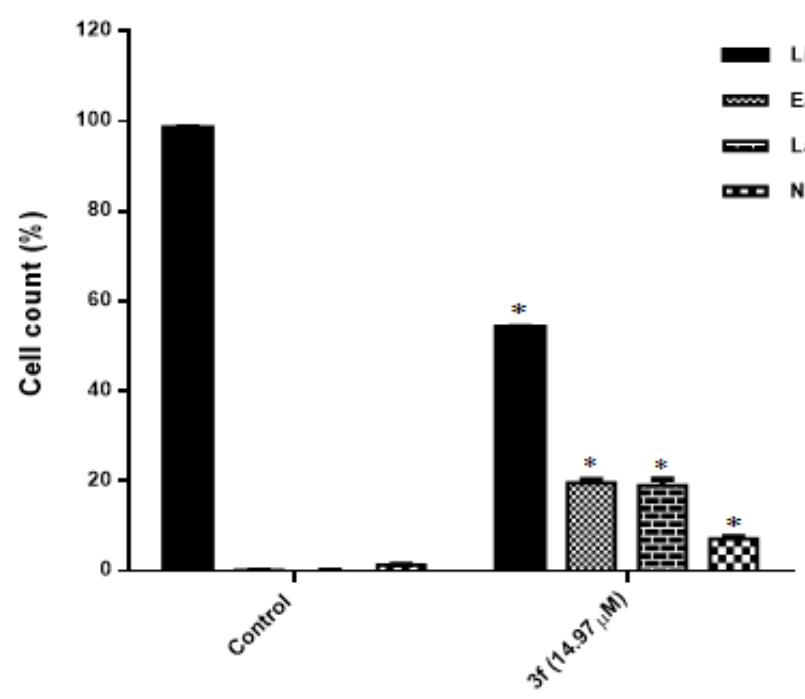

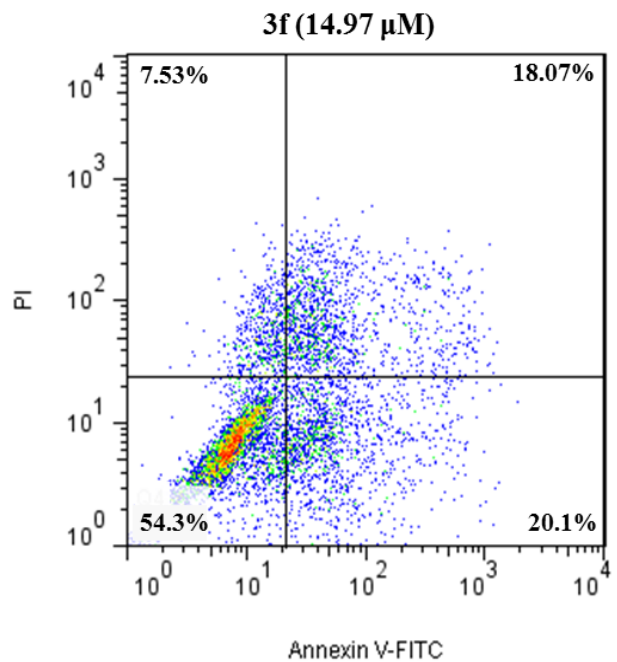

Annexin V-FITC

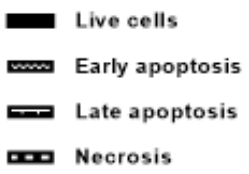

Figure 1. (a), The flow cytometry analysis of MDA-MB-468 cell line after $24 \mathrm{~h}$ treatment with $3 \mathrm{f}$ compound; (b), The percentages of live cells, necrosis, early and late apoptosis.

control sample (untreated cells) was calculated $38 \%$. In addition, as time elapsed up to $24 \mathrm{~h}$ treatment with $3 \mathrm{f}$

Table 2. $\mathrm{IC}_{50}$ Values of Novel Pyrazol Compounds and Paclitaxel after 24 and $48 \mathrm{~h}$ Treatment in MDA-MB-468 and AGO-1522 Cells

\begin{tabular}{lcccc}
\hline & \multicolumn{2}{c}{ MDA-MB-468 } & \multicolumn{2}{c}{ AGO1522 } \\
& 24 hours & 48 hours & 24 hours & 48 hours \\
\hline 3a & $* 25.00 \pm 0.92$ & $6.41 \pm 1.10$ & $28.80 \pm 0.95$ & $19.87 \pm 0.83$ \\
3b & $19.20 \pm 0.97$ & $9.29 \pm 0.67$ & $29.82 \pm 1.02$ & $19.78 \pm 0.96$ \\
3c & $58.61 \pm 0.82$ & $19.87 \pm 1.12$ & $24.10 \pm 0.65$ & $17.65 \pm 0.93$ \\
3d & $32.58 \pm 1.22$ & $15.25 \pm 0.90$ & $42.15 \pm 1.27$ & $35.57 \pm 1.32$ \\
3e & $21.31 \pm 0.85$ & $10.81 \pm 0.93$ & $42.79 \pm 0.98$ & $19.89 \pm 0.99$ \\
3f & $14.97 \pm 1.09$ & $6.45 \pm .84$ & $28.74 \pm 1.20$ & $20.33 \pm 0.83$ \\
3g & $25.83 \pm 0.91$ & $8.50 \pm 0.89$ & $43.30 \pm 0.96$ & $33.97 \pm 1.92$ \\
4a & $19.35 \pm 1.14$ & $11.03 \pm 0.88$ & $31.19 \pm 1.24$ & $14.48 \pm 0.97$ \\
4b & $58.20 \pm 1.35$ & $11.95 \pm 0.94$ & $34.56 \pm .89$ & $27.03 \pm 0.79$ \\
4c & $28.76 \pm 0.98$ & $12.42 \pm 0.79$ & $25.19 \pm 0.88$ & $20.95 \pm 0.92$ \\
4d & $58.58 \pm 1.32$ & $24.46 \pm 1.17$ & $34.41 \pm 1.31$ & $27.34 \pm 0.94$ \\
Paclitaxel & $49.90 \pm 0.97$ & $25.19 \pm 1.27$ & $42.93 \pm 1.42$ & $22.59 \pm 0.91$ \\
\hline *Data
\end{tabular}

*Data shown are mean \pm SD of triplicate samples compound, the intensities related to necrotic cells (stained with PI) and late apoptotic cells (stained with annexin V and PI) encountered a significant rise. Figure $1 \mathrm{~b}$ reveals that the early apoptotic stage of MDA-MB-468 cells (stained with annexin $\mathrm{V}$ ) in response to $3 \mathrm{f}$ compound increased significantly compared to the control sample. Accordingly, the finding could enable us to believe that apoptosis is the mechanism by which $3 \mathrm{f}$ compound triggers cytotoxicity in breast cancer cells.

$3 f$ leads to the accumulation of the MDA-MB-468 cells in the subG1 phase of the cell cycle

In the recent decade, an increasing interest toward applying cell cycle as a new approach for cancer therapy could be spotted among researchers. For instance, it is well established that there is a correlation between cell cycle progression and inhibition of cell proliferation and apoptosis in cancer cells (Cankara Pirol et al., 2014). We performed Flow cytometric analyses in combination with DNA staining using PI to study cells distribution in the different phases of the cell cycle. Our results revealed that treatment of triple negative breast cancer 
$\mathbf{a}$

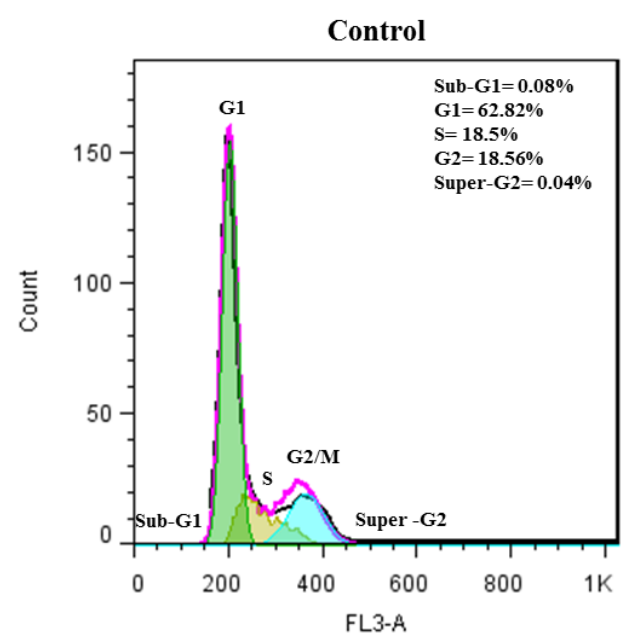

3f $(14.97 \mu \mathrm{M})$

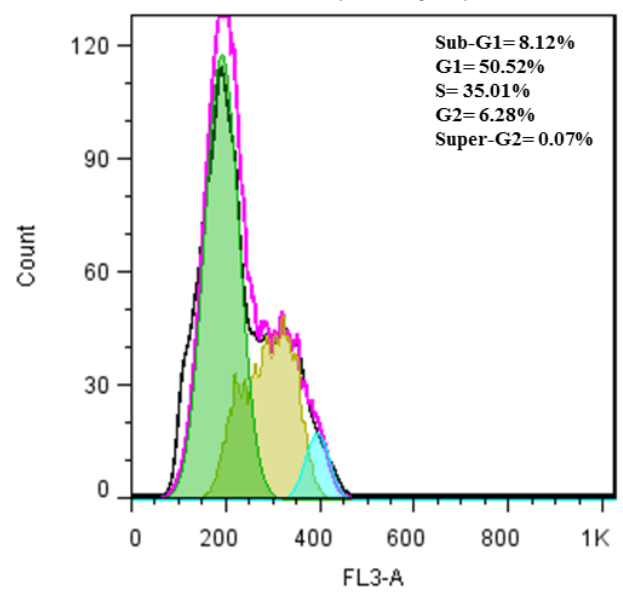

b

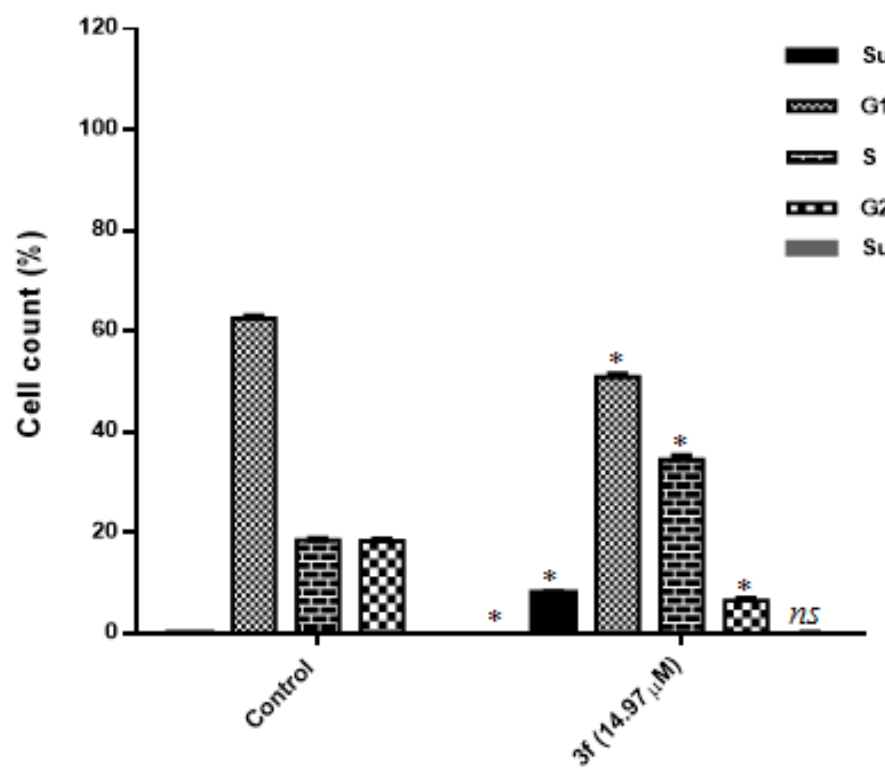

Figure 2. (a) The histograms of DNA content for MDA-MB-468 cell line treated with $3 \mathrm{f}$ for $24 \mathrm{~h}$. (b) the percentage of cell cycle distribution after $24 \mathrm{~h}$ treatment with $3 \mathrm{f}$ compound.

cells with $3 \mathrm{f}$ compound results in an increasing number of the cells at G0/G1 phase and S-phase. From Figure 2a, by introducing $14.97 \mu \mathrm{M}$ of $3 \mathrm{f}$ compound to the culture media of MDA-MB-468 for $24 \mathrm{~h}$, the fraction of cells at the $\mathrm{Go} / \mathrm{G} 1$ and $\mathrm{S}$ phase met a rise from $0.08 \%$ to $8.12 \%$ and $18.5 \%$ to $35 \%$ respectively. Calculation of cell cycle distribution pertinent to MDA-MB-468 cells revealed that treatment of cells with $3 \mathrm{f}$ compound for $24 \mathrm{~h}$ leads to an increase in cell death by apoptosis. Engaging the reaction process in Figure 2b, $3 \mathrm{f}$ could be considered as an effective inducer of apoptosis in triple negative breast cancer.

\section{ROS generation plays critical roles in $3 f$-induced cell death}

To study the role of reactive oxygen species in inducing apoptosis by compound 3f, DCFH-DA, a fluorescent probe, was used to quantify the level of ROS production. Accordingly, $14.97 \mu \mathrm{M}$ of $3 \mathrm{f}$ compound was added to the MDA-MB-468 breast cancer cells and then after $24 \mathrm{~h}$, the ROS level was measured by fluorimetry. From Figure 3a, an ascending trend pertinent to the intracellular ROS can be observed in MDA-MB-468 cells in the presence of $3 \mathrm{f}$ compound. This behavior may reflect that the induction of apoptosis in MDA-MB-468 triple negative breast cancer cells by $3 \mathrm{f}$ compound is linked to ROS production.

Caspase-3 activities in compound $3 f$ mediated apoptosis

The fluorimetric assay kit was applied to measure the activity of caspase- 3 as a major protease in apoptosis signaling. The representative caspase- 3 activity in MDAMB-468 cells in the presence and absence of 3 f compound has been depicted in Figure $3 \mathrm{~b}$. In the presence of $3 \mathrm{f}$ compound, the caspase activity significantly increased.

\section{Discussion}

Among many different types of breast cancer, TNBC is the most aggressive one with a higher frequency in minority populations (Kastrati et al., 2010). Even though chemotherapy is still one of the efficient ways to target cancerous tumors, the performance of these anticancer agents is limited to the selectivity of the drug by cancer cells 

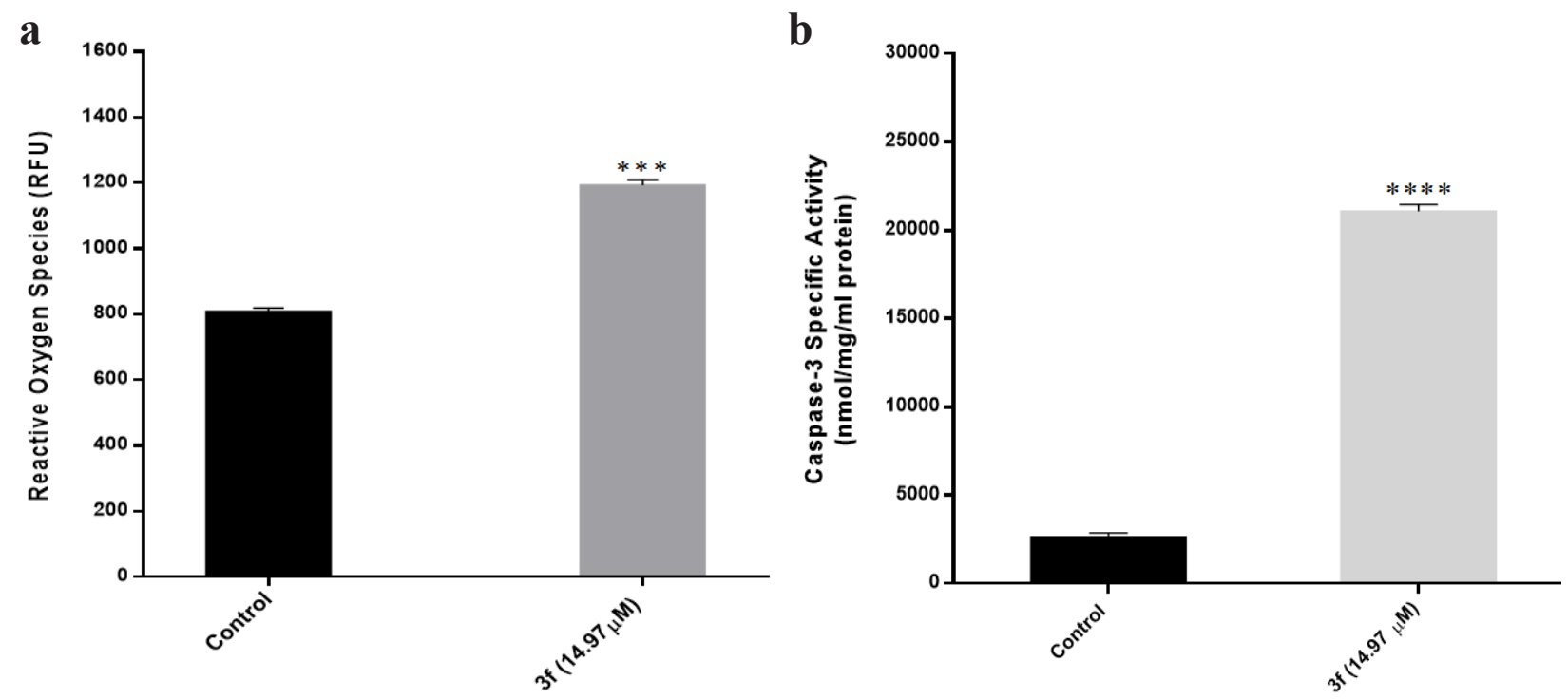

Figure 3. (a) The ROS generation after $24 \mathrm{~h}$ treatment with $3 \mathrm{f}$ compound. (b) The caspase-3 activation in MDAMB-468 cells after $24 \mathrm{~h}$ treatment with $3 \mathrm{f}$ compound. The measurement was performed by an enzymatic assay. An increase in caspase- 3 activation can be observed in response to $3 \mathrm{f}$ treatment.

and other tumor-related factors including the development of drug resistance over time (Atmaca et al., 2017). The rise of concern about the drawbacks associated with common drugs points up the need for more research toward a new generation of anticancer agents (Tessmann et al., 2017). On the basis of published data, heterocyclic compounds have been widely utilized in modern therapeutics (Saleh et al., 2016). Possessing a variety of biological properties including anticancer, antioxidant, antiinflammatory, antibacterial, antimicrobial, antidepressant, antiangiogenic, anti-influenza, and analgesic activities, Pyrazole derivatives have been documented as a promising compound for specific application in drug discovery (Inceler et al., 2013; Li and Zhao, 2014). In this research work, the impact of Pyrazole derivatives on the human triple negative breast cancer cell line was investigated. Our results revealed the anti-proliferation response of cancer cells to drug in a dose- and time-dependent manner. We assessed several synthesized Pyrazole derivatives and $3 \mathrm{f}$ exhibited a significant inhibitory response on cancer cells. The $\mathrm{IC}_{50}$ value obtained after $24 \mathrm{~h}$ treatment for MDA-MB-468 cancer cell and AGO1522 normal fibroblast cell line were recorded 14.97 and $28.74 \mu \mathrm{M}$ respectively, indicating the effectiveness of $3 \mathrm{f}$ compound on inhibiting the growth of human triple negative breast cancer cells. Our results are in agreement with the literature that reported the apoptosis effect of Pyrazole derivatives on cancer cells (Inceler et al., 2013; Sebastian et al., 2016; Ananda et al., 2018; Nossier et al., 2018). The regulated destruction of a cell or apoptosis is a vital physiological process in elimination and suppression of cancer tumors (Agarwal et al., 2018). Due to acquiring resistance by tumors, chemotherapy inducing apoptosis have been investigated through the years in the hope of finding a proper compound to overcome apoptosis resistance (Shahsavari et al., 2015; Fakai et al., 2019). In this research work, we used the Annexin-V/FITC and PI staining to understand whether apoptosis is involved in mechanism behind interaction of $3 \mathrm{f}$ compound and MDA-MB-468 cells. The results disclosed significant level of cell death by a major contribution of the apoptotic pathway. Pyrazole derivatives as an inducer of apoptosis in cancer cells have already been reported. Demetrio Raffa et al., (2019) studied a series of Pyrazole derivatives on a human lung carcinoma cell line and they revealed the apoptotic cell death by activating TRAIL death receptors followed by caspase- 8 activation (extrinsic pathway) or changes in p53 activation (intrinsic pathway). Another study (Czarnomysy et al., 2018) investigated the complexation of Pyrazole derivatives with platinum to enhance their therapeutic effect. The results associated with the interaction of two breast cancer cell lines and Novel Pyrazole platinum (II) complexes disclosed a higher percentage of DNA fragmentation indicating apoptosis via indirect DNA damage. Uncontrolled cell proliferation is the cancer's common traits as a result of mutated genes that directly control cell cycle (Kong et al., 2016). It is well established that the cell cycle progression inhibition is an efficient approach to hinder cancer tumor progression (Liu et al., 2016). There has been a great deal of research into potential benefits of targeting cell cycle including a possible opportunity to deal with acquiring drug resistance (Prasedya et al., 2016). In the present work, we observed a drastic rise of sub-G0/G1 DNA content in cells indicating significant increase of apoptotic cell death. A similar result was reported by Mohamed et al., (2014) who revealed a rise of G0/G1 phase for MCF-7 cells in response to the treatment with a synthetic compound containing Pyrazole ring. In an effort to introduce a new anticancer agent for bladder cancer, a series of pyrazoline derivatives was utilized on 5647 and T24 cells as two human bladder cancer cell line. The evidence provided revealed an inhibited cell cycle progression of 5637 cells in the presence of 1-thiocarbamoyl-3,5-diphenyl-4,5dihydro-1H-Pyrazole (2a) and 1-thiocarbamoyl-5-(4chlorophenyl)-3-phenyl-4,5-dihydro-1H-Pyrazole (2c). 
In addition, a dramatic increase of sub G0/G1 phase was observed which linked to the apoptosis (Tessmann et al., 2017).

According to the literature (Ji et al., 2013), a high amount of ROS may results in the oxidative destruction of cellular protein, lipids, nucleic acids and finally triggers the cellular death pathway through apoptosis or necrosis. Mitochondrial apoptotic pathway through ROS production is a ubiquitous feature of chemotherapeutic agents (Saleh et al., 2016). Therefore, novel chemotherapeutic agents regulating the accumulation of intracellular ROS may be considered as a promising approach to eliminate tumor growth (Tsai et al., 2017). Our study disclosed the selective growth inhibition of breast cancer cells, MDA-MB-468 corresponded to the $3 \mathrm{f}$ compound is associated with apoptosis pathway through ROS generation. Our results are in agreement with the literature (Xiong et al., 2019) that reported a novel thiazolyl substituted bis-pyrazole oxime compound selectively inhibited proliferation of colorectal cancer HCT116 cells by inducing apoptosis pathway through the promotion of intracellular ROS level. The therapeutic impact of a Pyrazole compound on angiogenesis in human umbilical vein endothelial cells (HUVECs) was studied by Zhang et al., (2011). They showed the Pyrazole compound induced angiogenesis by a significant increase of NO and ROS production through ROS-HIF- $1 \alpha$-VEGF and NO signaling pathways. To put it simply, the levels of HIF- $1 \alpha$ and VEGF in the presence of Pyrazole compound enhanced in a ROS dependent manner.

Cysteine proteases namely caspases play a vital role in the programmed cell death affecting the coordinated cascade for degrading cellular components (Cao et al., 2015). Caspase-3, as a member of the cysteine-aspartatespecific protease family, is a ubiquitous protein in mammalian cells contributing to apoptosis significantly (Zhao et al., 2014). The caspase-3 causes apoptosis pathway can be activated by a myriad of stimuli including chemotherapeutic compounds (Lepiarczyk et al., 2015). Herein, we evaluated whether caspase- 3 activation plays a role in the apoptosis triggered by $3 \mathrm{f}$ compound or not. We observed a significant rise of caspase- 3 enzymatic activity in the presence of $3 \mathrm{f}$ compound indicating this Pyrazole compound induced apoptosis in MDA-MB-468 cells. The evidence provided could lead us to believe that the caspase-dependent pathway is the significant mechanism which accelerates the apoptosis process induced by $3 \mathrm{f}$ compound in MDA-MB-468 cells. The cell growth attenuation, activation of caspase-dependent pathway, and fragmented DNA in HL-60RG leukemia cells induced by a Pyrazole compound was indicated by Nagahara and Nagahara, (2017). More recently, Harras et al., (2018) reported an excellent anti-cancer activity of a Pyrazole derivative against HCT116, UO-31, and HepG2 cells. They suggested a better cytotoxic activity of the Pyrazole compound in comparison with Sorafenib (a reference drug) through activation of caspases-3 dependent pathway.

In this research work the cytotoxicity of a series of Pyrazole derivatives including 3-(4-methoxyphenyl)-1(p-tolyl)-5-(3,4,5-trimethoxyphenyl)-4,5-dihydro-1HPyrazole namely 3 f on MDA-MB-468 cells were proved.
Evidence provided revealed the apoptosis activity of $3 \mathrm{f}$ compound on MDA-MB-468 triple negative breast cancer cells through ROS generation and caspase 3 signaling pathway. Therefore, it seems realistic to anticipate that Pyrazole derivatives might be used in the future and become a chemotherapeutic approach in cancer biology.

\section{Author Contribution Statement}

Dr. Zahra shahsavari and Dr. Faranak Kazerouni jointly worked on the design and implementation of project and preparation of the manuscript. Maryam Ashourpour and Fatemeh Mostafavi-Hosseini jointly worked on the project implementation, statistical analysis and preparation of the manuscript as MSc. Students. Mohsen Amini and Ebrahim Saeedian Moghadam synthesized the Pyrazole derivative. Dr. Yousef Arman contributed the manuscript writing and editing.

\section{Acknowledgments}

This work was part of a master's thesis supported by the Foundation of Shahid Beheshti University of Medical Sciences.

\section{Ethical statement}

The ethics committee of Vice president of research of Shahid Beheshti University of Medical Sciences with ethics committee code: IR.SBMU.RETECH. REC.1396.590 approved the project ethically.

\section{Conflict of interest}

The authors declare that there is no conflict of interest.

\section{References}

Abel SD, Baird SK (2018). Honey is cytotoxic towards prostate cancer cells but interacts with the MTT reagent: Considerations for the choice of cell viability assay. Food Chem, 241, 70-8.

Agarwal A, Kasinathan A, Ganesan R, et al (2018). Curcumin induces apoptosis and cell cycle arrest via the activation of reactive oxygen species-independent mitochondrial apoptotic pathway in Smad4 and p53 mutated colon adenocarcinoma HT29 cells. Nutr Res, 51, 67-81.

Alam R, Wahi D, Singh R, et al (2016). Design, synthesis, cytotoxicity, HuTopoII $\alpha$ inhibitory activity and molecular docking studies of pyrazole derivatives as potential anticancer agents. Bioorg Chem, 69, 77-90.

Ananda H, Kumar KSS, Sudhanva MS, Rangappa S, Rangappa KS (2018). A trisubstituted pyrazole derivative reduces DMBA-induced mammary tumor growth in rats by inhibiting estrogen receptor- $\alpha$ expression. Mol Cell Biochem, 449, $137-44$.

Atmaca H, Özkan AN, Zora M (2017). Novel ferrocenyl pyrazoles inhibit breast cancer cell viability via induction of apoptosis and inhibition of PI3K/Akt and ERK1/2 signaling. Chem Biol Interact, 263, 28-35.

Cankara Pirol S, Caliskan B, Durmaz I, Atalay R, Banoglu E (2014). Synthesis and preliminary mechanistic evaluation of 5-(p-tolyl)-1-(quinolin-2-yl)pyrazole-3-carboxylic acid amides with potent antiproliferative activity on human cancer cell lines. Eur J Med Chem, 87, 140-9. 
Cao A-L, Tang Q-F, Zhou W-C, et al (2015). Ras/ERK signaling pathway is involved in curcumin-induced cell cycle arrest and apoptosis in human gastric carcinoma AGS cells. $J$ Asian Nat Prod Res, 17, 56-63.

Czarnomysy R, Surażyński A, Muszynska A, et al (2018). A novel series of pyrazole-platinum (II) complexes as potential anti-cancer agents that induce cell cycle arrest and apoptosis in breast cancer cells. J Enzyme Inhib Med Chem, 33, 1006-23.

Dai H, Ge S, Guo J, et al (2018). Development of novel bis-pyrazole derivatives as antitumor agents with potent apoptosis induction effects and DNA damage. Eur J Med Chem, 143, 1066-76.

Fakai MI, Abd Malek SN, Karsani SA (2019). Induction of apoptosis by chalepin through phosphatidylserine externalisations and DNA fragmentation in breast cancer cells (MCF7). Life Sci, 220, 186-93.

Harras MF, Sabour R (2018). Design, synthesis and biological evaluation of novel 1,3,4-trisubstituted pyrazole derivatives as potential chemotherapeutic agents for hepatocellular carcinoma. Bioorg Chem, 78, 149-57.

Inceler N, Y1lmaz A, Baytas SN (2013). Synthesis of ester and amide derivatives of 1-phenyl-3-(thiophen-3-yl)-1Hpyrazole-4-carboxylic acid and study of their anticancer activity. Med Chem Res, 22, 3109-18.

Ji YY, Zhu YM, Wang JW (2013). GS-2, a pyrazolo [1, 5-a] indole derivative with inhibitory activity of topoisomerases, exerts its potent cytotoxic activity by ROS generation. Environ Toxicol Pharmacol, 36, 1186-96.

Jiang L, Yu X, Ma X, et al (2019). Identification of transcription factor-miRNA-lncRNA feed-forward loops in breast cancer subtypes. Comput Biol Chem, 78, 1-7.

Kastrati I, Edirisinghe PD, Wijewickrama GT, Thatcher GR (2010). Estrogen-induced apoptosis of breast epithelial cells is blocked by NO/cGMP and mediated by extranuclear estrogen receptors. Endocrinology, 151, 5602-16.

Kong Y, Chen G, Xu Z, et al (2016). Pterostilbene induces apoptosis and cell cycle arrest in diffuse large B-cell lymphoma cells. Sci Rep, 6, 37417.

Lehmann TP, Kujawski J, Kruk J, et al (2017). Cell-specific cytotoxic effect of pyrazole derivatives on breast cancer cell lines MCF7 and MDA-MB-231. J Physiol Pharmacol, 68, 201-7.

Lepiarczyk M, Kałuża Z, Bielawska A, et al (2015). Cytotoxic activity of octahydropyrazin [2, 1-a: 5, 4-a'] diisoquinoline derivatives in human breast cancer cells. Arch Pharm Res, 38, 628-41.

Li M, Zhao B-X (2014). Progress of the synthesis of condensed pyrazole derivatives (from 2010 to mid-2013). Eur J Med Chem, 85, 311-40.

Liu E, Li J, Shi S, et al (2016). Sustained ERK activation-mediated proliferation inhibition of farrerol on human gastric carcinoma cell line by G0/G1-phase cell-cycle arrest. Eur J Cancer Prev, 25, 490-9.

Liu Z, Zhang XS, Zhang S (2014). Breast tumor subgroups reveal diverse clinical prognostic power. Sci Rep, 4, 4002.

Mohamed MF, Mohamed MS, Fathi MM, Shouman SA, Abdelshafy Abdelhamid I (2014). Chalcones incorporated pyrazole ring inhibit proliferation, cell cycle progression, angiogenesis and induce apoptosis of MCF7 cell line. Anticancer Agents Med Chem, 14, 1282-92.

Nagahara Y, Nagahara K (2017). Relationship between structure and antiproliferative activity of novel 5-amino4-cyanopyrazole-1-formaldehydehydrazono derivatives on HL-60RG human leukemia cells. Anticancer Res, 37, 6329-33.

Nitulescu GM, Draghici C, Olaru OT, et al (2015). Synthesis and apoptotic activity of new pyrazole derivatives in cancer cell lines. Bioorg Med Chem, 23, 5799-808.

Nossier ES, Abd El-Karim SS, Khalifa NM, et al (2018). Kinase inhibitory activities and molecular docking of a novel series of anticancer Pyrazole Derivatives. Molecules, 23.

Prabhu VV, Elangovan P, Devaraj SN, Sakthivel KM (2018). Targeting apoptosis by 1, 2-diazole through regulation of EGFR, Bcl-2 and CDK-2 mediated signaling pathway in human non-small cell lung carcinoma A549 cells. Gene, 679, 352-9.

Prasedya ES, Miyake M, Kobayashi D, Hazama A (2016). Carrageenan delays cell cycle progression in human cancer cells in vitro demonstrated by FUCCI imaging. BMC Complement Altern Med, 16, 1-9.

Prat A, Adamo B, Cheang MC, et al (2013). Molecular characterization of basal-like and non-basal-like triplenegative breast cancer. Oncologist, 18, 123-33.

Raffa D, D'Anneo A, Plescia F, et al (2019). Novel 4-(3-phenylpropionamido), 4-(2-phenoxyacetamido) and 4-(cinnamamido) substituted benzamides bearing the pyrazole or indazole nucleus: Synthesis, biological evaluation and mechanism of action. Bioorg Chem, 83, 367-79.

Rakha EA, Reis-Filho JS, Baehner F, et al (2010). Breast cancer prognostic classification in the molecular era: the role of histological grade. Breast Cancer Res, 12, 207.

Saleh AM, Aziz MA, Abdou IM, et al (2016). Cytotoxic activity of the novel heterocyclic compound G-11 is primarily mediated through intrinsic apoptotic pathway. Apoptosis, 21, 873-86.

Saueressig S, Tessmann J, Mastelari R, et al (2018). Synergistic effect of pyrazoles derivatives and doxorubicin in claudinlow breast cancer subtype. Biomed Pharmacother, 98, 390-8.

Sebastian A, Pandey V, Mohan CD, et al (2016). Novel adamantanyl-based thiadiazolyl pyrazoles targeting EGFR in triple-negative breast cancer. ACS Omega, 1, 1412-24.

Shahsavari Z, Karami-Tehrani F, Salami S (2015). Shikonin induced necroptosis via reactive oxygen species in the T-47D breast cancer cell line. Asian Pac J Cancer Prev, 16, 7261-6.

Skiba J, Kowalczyk A, Stączek P, et al (2019). Luminescent fac-[Re (CO) 3 (phen)] carboxylato complexes with nonsteroidal anti-inflammatory drugs: synthesis and mechanistic insights into the in vitro anticancer activity of fac- $[\operatorname{Re}(\mathrm{CO})$ 3 (phen)(aspirin)]. New J Chem, 43, 573-83.

Tao Z, Shi A, Lu C, et al (2015). Breast cancer: Epidemiology and Etiology. Cell Biochem Biophys, 72, 333-8.

Tessmann JW, Buss J, Begnini KR, et al (2017). Antitumor potential of 1-thiocarbamoyl-3, 5-diaryl-4, 5-dihydro$1 \mathrm{H}$-pyrazoles in human bladder cancer cells. Biomed Pharmacother, 94, 37-46.

Tsai C-H, Hung AC, Chen Y-Y, et al (2017). 3'-hydroxy-4'methoxy- $\beta$-methyl- $\beta$-nitrostyrene inhibits tumorigenesis in colorectal cancer cells through ROS-mediated DNA damage and mitochondrial dysfunction. Oncotarget, 8, 18106.

Xiong B, Chen S, Zhu P, et al (2019). Design, synthesis, and biological evaluation of novel thiazolyl substituted bis-pyrazole oxime derivatives with potent antitumor activities by selectively inducing apoptosis and ROS in cancer cells. Med Chem, 15, 743-54.

Yersal O, Barutca S (2014). Biological subtypes of breast cancer: Prognostic and therapeutic implications. World J Clin Oncol, 5, 412-24.

Zhang H-y, Su L, Huang B, et al (2011). N-benzyl-5-phenyl-1 H-pyrazole-3-carboxamide promotes vascular endothelial cell angiogenesis and migration in the absence of serum and FGF-2. Acta Pharmacol Sin, 32, 209-16.

Zhao J, Ming Y, Wan Q, et al (2014). Gypenoside attenuates 
hepatic ischemia/reperfusion injury in mice via anti-oxidative

and anti-apoptotic bioactivities. Exp Ther Med, 7, 1388-92.

\section{(ख) (1) 8}

This work is licensed under a Creative Commons Attribution-

Non Commercial 4.0 International License. 